\title{
FIXES, a System for Automatic Selection of Set-Ups and Design of Fixtures
}

\author{
J. R. Boerma, H. J. J. Kals (1); Laboratory of Production Engineering, University of Twente \\ Received on January 18,1988
}

\begin{abstract}
This paper reports on the development of a computer aided planning system for the selection of set-ups and the design of fixtures in part manufacturing. First, the bottlenecks in the present planning methods are indicated. A brief description is given of the C.APP environment PART, in which FIXES is incorporated. The planning procedure of FLXES consists of two parts: the selection of set-ups and the design of a fixture for each set-up. The automatic selection of set-ups is based on the comparison of the tolerances of the relations between the different shape elements of the part. A tolerance factor has been developed to be able to compare the different tolerances. The system automatically selects the positioning faces and supports the selection of tools for positioning, clamping and supporting the part. A prototype implementation of FIXES is discussed.
\end{abstract}

KEIWORDS: jigs \& fixtures, sel-up. clamping. design, process planning. CAPP, CAM

\section{Introdluction}

Process Planning is one of the main bottlenecks in flexible manufacturing of parts in small batches. A large portion of the time and cost of workpreparation is spent on the selection of set-ups and the clesign of fixtures. Also time-consuming and costly is the construction of fixtures and the acculate positioning on a machine tool. Significant improvements in flexibility and throughput time can be achieved by improving the fixturing process. This paper deals with the description of a system, which can automatically select set-ups and which provides an efficient tool for the design of fixtures.

The fixturing process consists of both the selection of the set-ups required to machine a part according to the given specifications and the clesign of the different fixtures. With reference to present planning methods, the process planner is simultaneously engaged in the selection of machine tools, set-ups. machining methods, cutting tools and fixture components. His decisions are based on experience and are limited by the geometrical constraints stated in the part drawings and by the arailable equipment.

The most important bottlenecks in present fixturing methods are:

- it takes much time to realize a tixture

- results largely depend on the capabilities of the process planner

- tixture knowledge is restricted to individual persons

- the finally accomplished accuracy of a fixture is difficult to predict

- there is a lack of flexibility, resulting in (i) a new fixture for each

problem and (ii) a large amount of fixturing tools.

Present fixturing knowledge is not available in an explicit form (e.g. as formalized procedures). This has hanpered the development of adeciuate fixturing methods and, in contrast with other planning functions, explains the lack of interest in carrying out research and education programs concerning fixturing.

However. against the background of continuous developments in the field of CAD/CAM, there is an increasing need to use the computer for fixturing as well. This requires an analysis of the present knowledge and the development of methods, which are based on this knowleclge. Inportant requirements for a computer aided fixturing system are:

- it must be a generative system, being able to generate "best solutions"

- it must be able to generate alternative solutions on request

- it must be capable of storing solutions

- it must be interfaced to other CAD/CAM functions

In order to derelop such a fixturing system, an analysis has been carried out of both the workprepasation methods concerning fixturing and the functions of fixtures. This has resulted in the definition of a system. which meets the above mentioned requirements.

\section{The environment of FIXES}

\subsection{The process planning system PART}

The use of a generative system for the selection of set-ups and the design of fixtures will only be efficient if it is integrated with the other proces planning functions. At the moment a prototspe of such an integrated process planning system, called PART, is under development in our laboratory (1). See fig. 1 The PART system contains five main modules covering the machine tool selection (MTS), the selection of set-ups and design of fixtures (J\&F), the selection of machining methods (MIM). the selection of cutting tools (TS) and the selection of cutting conditions selection of cutting tools (TS) and the selection of cutting conditions
(CC). The different modules are controlled by a so-called supervisor. (CC). The different modules are controlled by a so-called supervisor,
which consults pre-defined scenarios. A common database is recuired to achieve consistency of data and fast data exchange between the modules. Another important aspect is the use of a product modeller. The modeller can generate complete, exact and unambiguous 3-D part representations. which are directly accessible for automated information processing. Mos of the available $3-D$ modellers are of little or no use for manufacturing of the arailable $3-D$ modellers are of itte or no use for manufacturing technological information $(2,3,4,5)$. The PART system uses a boundary representation solid modeller (GPM) $(1,2)$ with exact geometry representation and offering facilities to store technological information like tolerances and material specifications. The V'E module is a use interface to the modeller and enables the operator to interactively create. manipulate and visualize a product model. A common user interface emphasizes the integration of functions in the system. The FR module is described in the next paragraph. The FIXES system covers the J\&F module.

2.2. Product model and feature definition

Information exchange between the design and the manufacturing department is traditionally carried out by means of technical part drawings. To ensure the functionality of the part, the designer adds geometric specifications, such as tolerances, to the 2-D drawing. In order to manufacture the part, the process plannel has to read and interpret this data. This twofold translation of information (to and from the drawing) can easily cause misunderstandings and errors. The application of an adequate solid modeller in the design stage eliminates the $2-D$ drawing as a data bridge between the designer and the process planner.

The use of shape elements, so-called features, enables direct access of the data of the product model for planning purposes. A feature is a the data of the product model for planning purposes. A feature is a
distinctive or characteristic part of a part defining a geometrical shape, distinctive or characteristic part of a part defining a geometrical shape,
which is ejther specific for a machining process and/or can be used for fixturing or measuring purposes (2). Examples of features are a hole, a pocket, a slot, a (plane) face, etc. A face can be a feature, but also a part of a feature. The characteristics of a feature are described by feature parameters. The feature recognition module (FR) of the PART system is developed to enable access to the data of the product by the different PART modules: the FR module automatically searches a given product model and recognizes the different features and assigns values to the feature parameters $(2,6,7)$. Each module of PART is designed to work with these features.

The geometrical requirements of a part are expressed as geometrical relations between the different features. The machining of a feature requires a particular orientation of the feature with regard to the machine tool axis: the feature orientation (F.O.). Each feature is provided with at

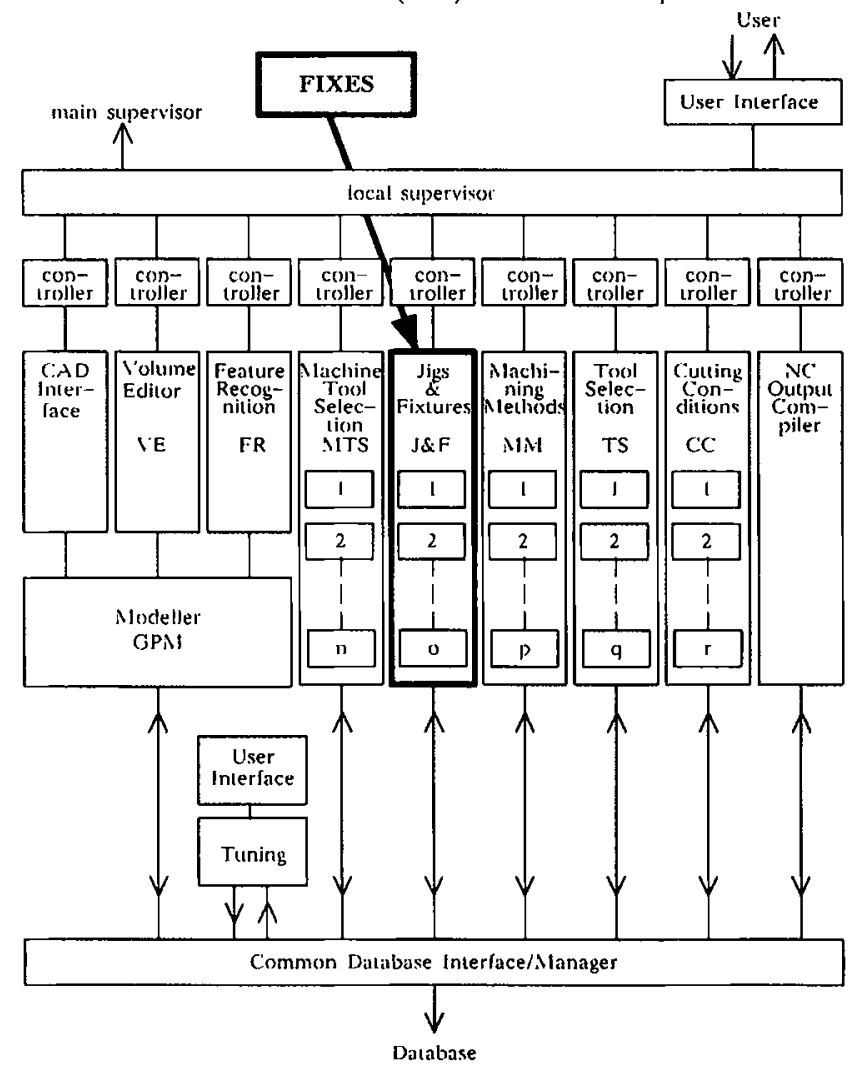

Fig. I. Schematic representation of the PART system

least one default F.O. Some features can have more than one F.O. (e.g. a (hrough-thole). 


\section{The FIXES system}

\subsection{The planning functions in FIXES}

The fixturing process contains two important planning functions: (i) the selection of set-ups and (ii) the design of the fixtures.

The primary functions of a fixture are to position, to clamp and to support the part $(8,9,10,11)$

The process of fixturing starts with set-up selection and continues with the design of a fixture for each set-up. First, the system selects the features of the part which have to be machined in one set-up. The selection depends on both the accuracy of the geometrical relations

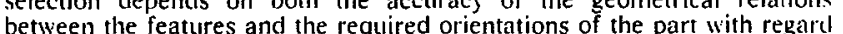
between the features and the required orientations of the part with regart
to the machine tool axis. The design of a fixture starts with the selection to the machine tool axis. The design of a fixture starts with the selection
of the positioning faces of the part. The selection depends on geometrical relations, in this case between existing features of the pait and the features which still have to be machined. Next, the clamping and supporting faces are selected, followed by the selection of the positioning. clamping and supporting tools. The tools are selected from a fixed tool-set. Finally, output data is produced both for assembly of the fixtures and for use in the following planning processes.

3.2. The set-up selection

The features. which have been extracted from the product model represent the information necessary for fixturing, machining and measuring the part. The features which have to be machined have to be arranged in groups (= set-ups). Each set-up requires a fixture. The number of fixtures has to be minimized because of cost and time involied in the realization of each fixture.

The machining of a feature results in a more or less accurate position of the machined feature with respect to the machine tool coordinate system. This position is lost if the part is dismounted from the machine tool and mounted again in a clifferent fixture.

The errors in the alignment of the fixture on the machine tool can be equal to or larger than the accuracy requirements of small-tolerance relations. As a result, the position accuracy of a feature, which has already been machined in a previous set-up, can be insufficient to realize the required accuracy in the relations between that feature and the ones which have to be machined in the present set-up. See fig. 2. So. closely related features have to be machined in one set-up, while less accurately related features can be machined in different set-ups. Therefore, the set-up selection has to be preceded by an evaluation of the tolerances concerning the geometrical relations between the different features. After that, the most accurate relations are selected and the corresponding features become primary candidates to be arranged in one set-tuls. Howerer. a set-up can contain only a limited number of different feature orientations (the maximum number depends on the machine tool configuration) So only those candidate features are selected uhich feature orientations fit in the set-up. In this way. the selected set-ups feature orientations fit in the set-up. In this was. the selected set-tips
result in minimum requirements for alignment of the different fixtures. 3.3. Fixture design

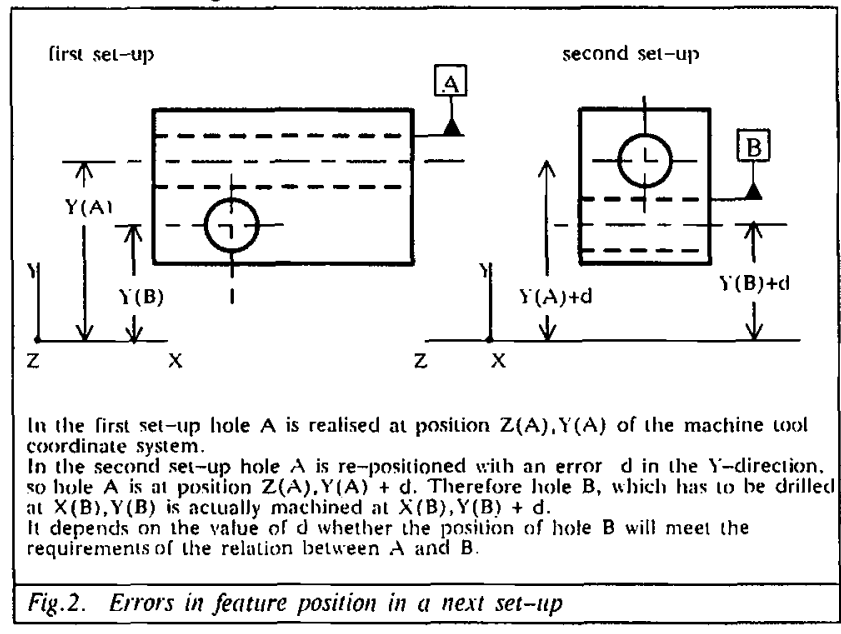

Fixture design includes: (i) the selection of faces of a part. which are best stited for positioning, clamping or supporting functions, and (ii) the selection of the corresponding fixture components, which are put together into a configuration to represent a fixture. In many cases the fixture consists of a standard baseplate and sepatate positioning, clamping and supporting tools

\subsubsection{Positioning}

Features which are dealt with in a given set-up, can have explicitly defined geometrical relations with features which have to be machined in a next set-up. Within a set-up. already existing features carrying the most important relations with the features which still have to be machined, serve as reference features and have to be located at prescribed positions of the machine tool coordinate system. See fig.3. prescribed positions of the machine tool coordinate system. See fig.3.
The faces which are actually used to position the part. are the so-called pasitioning faces. In most cases, reference features include the positioning faces. Only in those cases where the relative size of the reference feacures is small and/or the features are badly distributed, one has to look for separate positioning faces. See fig.4.

The first stage in the positioning procedure is to find the best suited reference features. The extent to which the requirements of the relations between the existing features and the features which still have 10 be machined are met, depends on the accuracs with which the part can be positioned. The magnitude of position errors (both translation and rotation errors) are dependent on: (i) the positioning faces which have
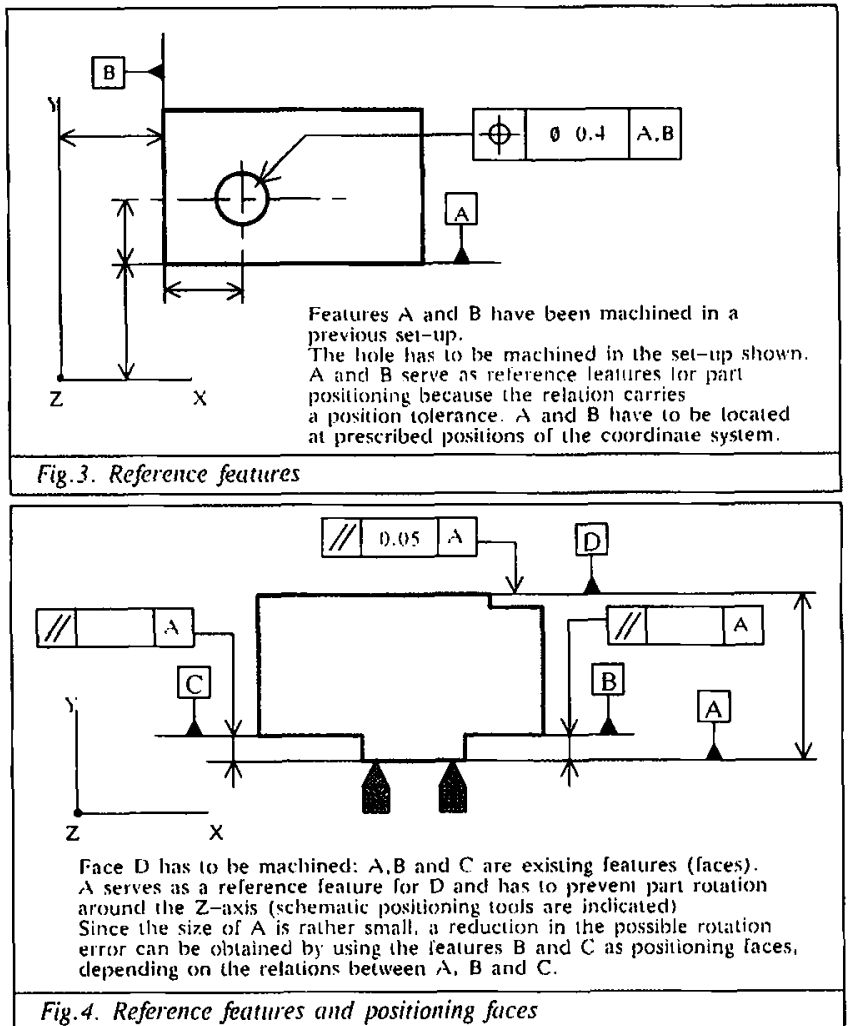

been selected and (ii) the realized geometric accuracy and mechanical stability of the fixture.

The translation errors resulting from inadequate part alignment can be compersated by the machine tool control system. which means that they need to be considered in the planning procedure. Contrary to this. rotation errors cannot be compensated; the required relation can best be realized when the corresponding features are machined in one set-up. But this is not possible when the clifferent F.O.'s coincicle.

The selection of the positioning faces for a given set-up is based on: - a comparison of the accuracy of the relations between the already existing features and features which still have to be machined; this results in the selection of the reference featules

- the distance between the features which have to be machined and the leference features

- the distance between the potential positioning faces

- the orientation and position of a potential positioning face relative to the remainder part of the workpiece

- the characteristics of the faces: size, type, rolghness, shape tolerance. orientation and position with regard to the baseplate

The first four items are of primary importance with respect to rotation errors in the position of the part. The last item is important with respect to the selection of the positioning tools.

\subsubsection{Clamping}

The clamping function is performed by locking the part to the supporting tools by means of one or more clamping tools. During the clamping process. the position of the part has to be determined by the positioning toots and must not be influenced by the clamping forces. See fig.5. In this design stage of the fixture. the part is considered to be rigid (no deflections). First. the primary supporting faces are selected. Positioning faces are the first candidales to become primary supporting faces; they are selected depending on the size and the estimated load. Positioning faces which do not meet the requirements of sufficient strength will be assisted by additional stpporting faces in the vicinity of the positioning faces. Subsequently, the clamping faces are as much as possible selected at locations opposite to the supporting faces.

3.3.3. Secondary support

Under normal conditions, a part will always deflect uncier the clamping and the machining load. If the estimated deflections of a part are large that is allowed by the prescribed tolerances, then so-called secondar supporting components are required. The selection of secondary supporting faces is based on the available faces, the locations of maximum deflections and the deflection magnitudes.

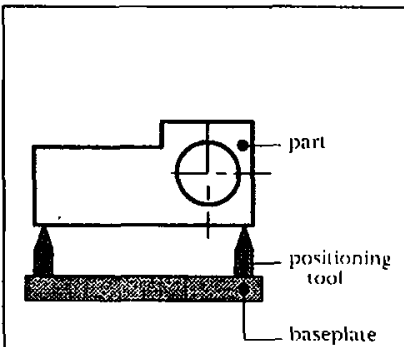

positioning

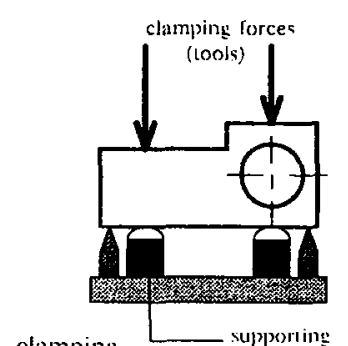

clamping

iool

Fig. 5 . The clamping of a part 
3.3.4. Integration with the other plamning functions

FIXES (the J\&F module) is used in two phases of the planning process (i) set-ups are selected after the selection of a machine tool and (ii) fixtures are designed after the selection of the machining methods and the culting tools. This sequence results from the input requirements for both set-up selection and fixture design, as can be seen in the following table

\begin{tabular}{|c|c|c|c|}
\hline \multicolumn{4}{|c|}{ set-up selection } \\
\hline imput & from & outpu & 10 \\
\hline the realures of a given part & $\mathrm{FR}$ & fealures with set-up parameters & MNI \\
\hline the relatinns between the fealures & $\mathrm{FR}$ & \multirow{2}{*}{$\begin{array}{l}\text { the set-ulp dala: the tealures per } \\
\text { set-up and the F.O.'s con- } \\
\text { lained in ench set-up }\end{array}$} & MIN \\
\hline \multirow{4}{*}{$\begin{array}{l}\text { The restrictions in F.O.'s per } \\
\text { sel-up: (i) maximum number } \\
\text { (ii) combinations }\end{array}$} & MTS & & \\
\hline & & \multirow{2}{*}{$\begin{array}{l}\text { lie gennetrical relations belween } \\
\text { Ihe sel-ups }\end{array}$} & \\
\hline & & & \\
\hline & & the sequence of sel-upss & MAI \\
\hline \multicolumn{4}{|c|}{ Eixlure design } \\
\hline inpout & [rom & sutpot & (ti) \\
\hline $\begin{array}{l}\text { The fentures belonging to a } \\
\text { given set-up }\end{array}$ & $J \& F$ & \multirow{3}{*}{$\begin{array}{l}\text { fixlure data: (i) the selected fix- } \\
\text { lure tools, (ii) lesation of the } \\
\text { positioning, clamping and sup- } \\
\text { porting [aces. (iii) leatures } \\
\text { corresponding with the selected } \\
\text { faces }\end{array}$} & \multirow[t]{3}{*}{$\begin{array}{ll}\mathrm{CC} \\
\mathrm{NC}\end{array}$} \\
\hline the relations between the lealures & $J \& F$ & & \\
\hline $\begin{array}{l}\text { lhe pint dala: } \\
\text { (i) veighl } \\
\text { (ii) dimensions }\end{array}$ & GPM & & \\
\hline estimated machining forces & M.M. & \multirow{3}{*}{$\begin{array}{l}\text { Tocation of the lixture relative to } \\
\text { the macline tool coordinate } \\
\text { sistem }\end{array}$} & \multirow{3}{*}{$\begin{array}{l}\mathrm{CC} \\
\mathrm{NC}\end{array}$} \\
\hline \multirow[t]{4}{*}{ datil ol available lixcure louls } & TS & & \\
\hline & & & \\
\hline & & location of the part & $\begin{array}{l}\mathrm{CC} \\
\mathrm{NC}\end{array}$ \\
\hline & & $\begin{array}{l}\text { instruction data for fixture } \\
\text { assembly }\end{array}$ & user \\
\hline
\end{tabular}

\section{The set-up selection process}

4.1. Feature relations and the conversion of tolerances

The two main objectives of the set-up selection procedure are: (i) to reduce the number of critica! tolerances in the geometrical relations between features belonging to the different set-ups, and (ii) to keep the number of set-ups as low as possible. The importance of the filst objectise is directly related to the positioning requirements of the part and as such with the ease with which a fixture can be realized. The second objectise is purely an economic one.

An important part of the selection procedure deals with the comparison of the significance of the different tolerances in the relations between the features. But. different tjpes of tolerances cannot directly be compared: therefore, the values have to be converted to non-type-specific values. For the purpose of comparison. a so-called tolerance factor (T.F.) has been introduced

In the present context. a tolerance value is a representation of the aclmissible deviation from an exactly defined relation between two features. Of two related features one is always selected as the reference feature (REF), while the other is defined as the tolerance feature (TOF). A tolerance represents a type and a value, defined over a given length. Each tolerance can basically be related to errors caused by nisalignments in the three principal directions. Depending on the type of tolerance. positioning errors can be composed of rotation and/or translation errors. But the errors caused by rotational misalignment Besides that Iranslation errors can be compensated by the machine tool controller. This means. that only the possible errors due to rotational misalignment in the three principal directions are of importance in the planning phase. The admissible errors in each of the three directions are calculated. A tolerance is converted into a tolerance factor by dividing the tolerance value by the representative length. This length depends on the type of tolerance and the dimensions of the part: see fig. 6 . So the T.F. represents the tangent of the maxinum admissible angle of rotation of the fenture concerned see fig. 7. The icon admion of the relations between the features results in a converted tolerance scheme. An example is shown in figs.8.a \& b. The T.F. covering the relation beticen feature $I$ and 3 is the smallest. Therefore feature $l$ and 3 hale to be machined in one set-lip. The nent smallest T.F. snggests, that feature 2 has to be ussigned to the same set-llp, provided that the F.O. of feature 2 can be combined with the F.O. 's of the features $I$ and 3 .

4.2. The procedures for set-up selection

As explained before, the selection of set-ups depends on: (i) the accuracy of the relations between the features, (ii) the F.O.'s of the feature involved and (iii) the number and clirections of the machine tool axes

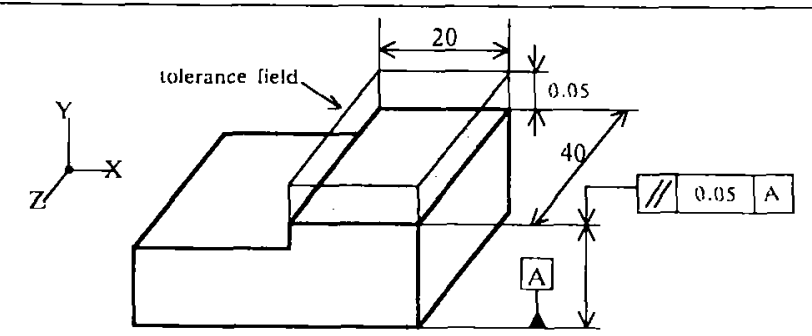

Pirallel tolerance with two relewant lengtlss around the $x$ and $z$ axes Admissable rotition around $X$ : relevant lenglh: $f(t)$ rotation watue $R X=0.05 / 41)$ Adinissalsle rotation around $Z$ : relevam length: 20 ; rotalion salue $R Z=0105 / 211$

The grey face is the so-called coletince feature (TOF), Face $A$ is colled the relerence feature (REF).

Fig.6. Relevant lengths of a tolerance

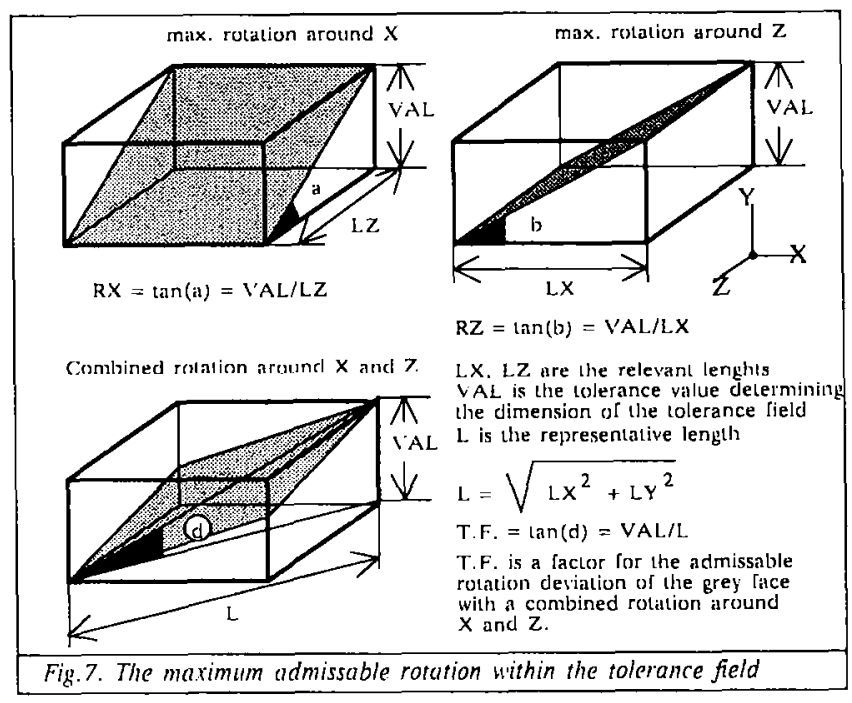

During the set-up selection only a subset of feature relations is considered. This subset contains the relations between the features which have to be machined and in which the two features involsed have a different F.O. The last recuirement is needed, because related features with identical FO's can alwass be machined in one set-up and do not cause problems. Related features with different F.O.'s often have to be machined in different set-ups and can cause accuracy problems. The corresponding relations are the critical ones in the set-up selection proceclure.

The procedure is based on the following assumptions: (i) all the features of the product model have been recognized and the parameter values have been assigned, (ii) the machine tool configuration has been selected, so the limitations to the F.O.'s are known, (iii) the data belonging to the convelted tolerance scheme and the T.F.'s have been calculated. (iiii) only those relations which contain features with different F.O.'s are taken into account.

The main procedure of set-up selection:

1. assign one single F.O. to each feature (procedure I)

2. select the set-ups (procedure ll)

3. deternine the sequence of set-ups (procedure III)

procedure 1: assign one single F.O. to each feature

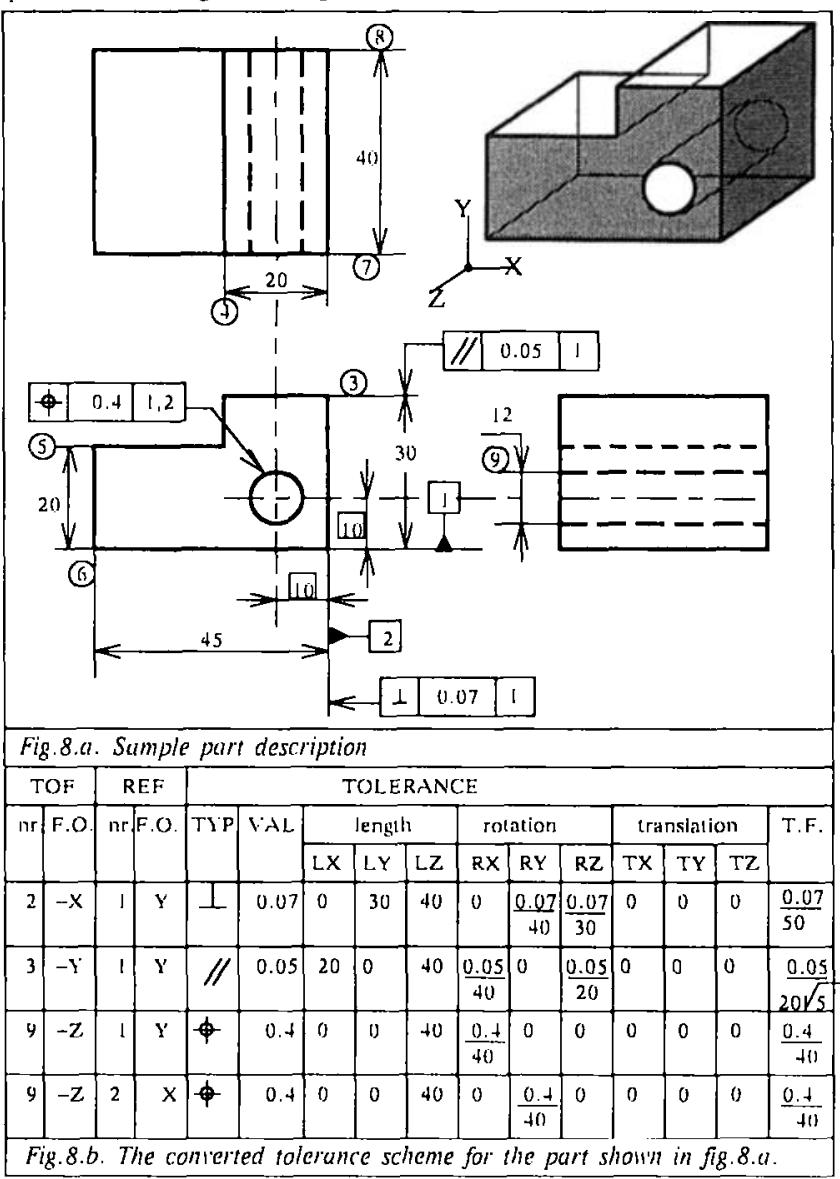

For a feature containing more than one F.O. (e.g. a through-hole), the best suited F.O. is found by scanning all the relations which refer to thit feature as a TOF and by selecting the relation with the smallest T.F. The 
F.O. of the corresponding REF may be the wanted F.O. If not, the problem is to complex to discuss here.

procedure II: select the set-ups

The procedure is based on a machining center with a one axis turning table including a corner plate ( 3 usable directions), which implies that : set-ups can contain at most 3 F.O.'s with the orientations in one plane Some definitions:

- set-up base: the 3 first selected features, which form the basis of a set-up

- incomplete set-up: a set-up contains less F.O.'s than is admissible

- non-assigned feature: the feature is not yet assigned to a set-up

the procedure:

1. select the set-up base

1. select the relation with the smallest T.F. The features contained in this relation determine two F.O.'s of the set-up base

2. determine the third F.O. of the set-up base:

Find the relation with the smallest T.F. from all other relations containing either the TOF or the REF of the set-up base relation. If the F.O. of the candidate third feature is fitting in the sel-up and if this relation contains either the TOF or the REF then add the candidate third feature to the set-up base.

2. attach the non-assigned features to a set-up

3. combine set-ups which contain coinciding F.O.'s

procedure III: determine the sequence of the set-ups

The sequence of set-ups is determined by the following rule of thumb: the last set-up contains on the average the most accurate relations. The first set-up is left with the less accurate relations.

\section{The positioning process}

5.1. The use of features for positioning

For positioning purposes a subset of alt features is taken into account. Pet set-up are considered: (i) the features which have to be machined, (ii) the already present features and (iii) the geometrical relations between the two kinds of features.

Just like in the set-up selection procedure, the tolerances of the relations are converted to tolerance factors. The smallest tolerance factors determine the maximum admissible rotation and translation errors of th part during fixturing. As explained before, rotation errors of the part cannot be compensated by the machine tool controller; therefore they must be under control during fixturing. Rotational errors in part position can be reduced by (i) an increase in the distance between the positioning faces and by (ii) a decrease in the distance between the REF ant the TOF.

For practical reasons, only faces parallel to the axes of the part coordinate system are suited as positioning faces.

The selection of the positioning faces is carried out in three stages: (i) select the positioning planes. (ii) select the reference features and (iji) select the positioning faces.

\subsection{The automatic selection of the 3 positioning planes}

Positioning of a part is based on the so-called 3-2-1-method to restrain the 6 degrees of freedom. The 3 positioning directions coinciding with the reyuired 6 positioning faces, constitute the normals of the 3 positioning planes: see fig. 9.

The selected 3-plane restricts 2 rotations and 1 translation of the part; the 2 -plane restricts 1 rotation and 1 translation; the 1-plane restricts 1 translation only. So, the F.O. of the REF connected with the relation which shows the two smallest rotation values in the converted tolerance scheme. determines the orientation of the 3-plane. Subsequently, the orientation of the 2-plane is selected by looking for the relation which orientation of the 2-plane is selected by looking for the relation which
shows only one smallest rotation value in the remaining direction; finally the selection of the 1-plane is a trivial one

\subsection{The selection of the reference features}

First, the reference features for positioning have to be determined. The first reference feature is found by selecting the relation with the smallest T.F. The REF of this relation is not necessarily the same as the REF which defines the direction of the 3-plane or 2-plane. although in many cases it is. The F.O. of the selected REF has to coincide with the orientation of one of the positioning planes (otherwise the feature cannot be used for positioning). The other reference features also are selected. based on T.F. and F.O. The selection is completed when at least one based on T.F. and F.O. The selection is completed when at least one
reference feature is found for each of the three positioning planes. In case of complex features (e.g. a deep pocket), it is theoretically possible that one feature can serve as a reference feature in each of the three principal directions; e.g. if the bottom face of the pocket is used as 3-plane and two of the sides as respectively 2-plane and J-plane, then the positioning procedure is completed. To recognize such cases. each reference feature has to be examined for possible use in more than one direction.

5.4. The selection of the positioning faces

The positioning faces are selected on the basis of the previous selected reference features. According to the 3-2-1-method, 6 positioning faces are required to position the part. A reference feature is the first candidate to provide one or more faces as positioning faces. The feature will be

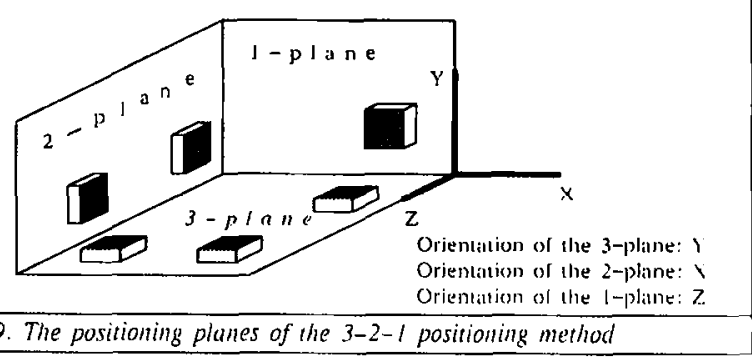

rejected if it does not meet the requirements of positioning faces: see 3 . and fig. 4 . If the feature can be split up into 3 separate faces with the same direction, it can on its own serve as the reference feature for a 3-plane If $\mathrm{not}$ one or two extra reference features are needed to create the 3-plane. The extra features are selected just like all the other reference features.

6. The implementation of FIXES

Since January 1983 the Laboratory of Production Engineering is involved in the development of a computer aided fixturing (CAF) system. The first protorype, built for an industrial firm. was delivered in 1985 (12). This early prototype, called the CAF-system, represents an early version of a fixturing system, with a limited functionality. A technical drawing serves as the input of the CAF system. The data of the drawing are converted by hand into lists. witich contain the relations between the faces. The hand into fists. Which contain the relatons berween in the FIXES system but without using the tolerance factor. The functionality of the system but without using the tolerance factor. The functionality of the
design procedure is limited to the selection of positioning faces and positioning components. A limited set of modular positioning elements is available.The system deternines the locations of the positioning components and finalls integrates the components in the fixturing configuration. A part list and a coordinate list are generated automatically. Presently, the system is in use in a job shop environment at Werkspoor Sireek b.y.

The FixES project started in June 1985 (13). Since then, a more sophisticated method for both the selection of set-ups and positioning faces has been developed. based on an accurate comparison of tolerances (14). The implementation of the procedures for the selection of both the set-ups and the positioning faces is finished. Present work is directed towards the development of procedures for the selection of the clamping faces and tools for positioning and clamping.

\section{Conclusions}

During the last decade it has frequently been suggested, that despite the use of sophisticated CNC machine tools and computer aided NC-program generation, it would be impossible to achieve real flexible manufacturing conditions, because, after having solved the problems of automation of machining, tooling, loading and transport, the fixturing problem would still require an unecyual large effort in time and cost. Today, it can be demonstrated, that by systematic analysis of the activities of the planning clepartment and by formalizing step by step the functions in the planning fixturing does no longer need to be a bottleneck in computer aided process planning.

\section{Acknowledgments}

The authors like to thank N.I. F.J.A.M. van Houten for the many rauluble contributions to the development of CAF and FIXES. His guidance in the design of the outline of the process planning environment is also gratefully acknowledged. The investigations are supported by the Netherlands Foundation for Technical Research (STW). Technical Science Branch of the Netherlands Organization for the Advancement of Pure Research (ZWO). The developments of the CAF-system have been supported by Werkspoor-Sneek b.r.

\section{References}

1 Kals,H.J.J., Van Houten.F.J.A.M., et al.: Research proposal for the 3.5 man-year SPIN project "Een werkvoorbereidingssy'steem" (an integrated process planning environment). Report PT 323, Twente University of Technology, july 1987 (in Dutch)

2 Erve,A.H.van ' $t$,: Generative computer aided process planning for part manufacturing, Ph.D. Thesis, University of Twente, 1988

3 Kimura,F.,Suzuki,H., W'ingard.L.: A uniform approach to dimensioning and tolerancing in product modelling. Proceedings of the Int. Conf. on Computer Aided Engineering (CAPE), Edinburgh, april 1986

4 Chang, T.C.Joshi,S.B.: CAD interface for autonuated process planning, 19 th CIRP Int. Seminar on Manuf. Systems, Penn. State Univ.. 1987

5 Yoshikawa,H.,Uehata,K.: Design theory for CAD/CAM integration, Annals of CIRP, rol. 34/1/1985

6 Erve,A.H.van ' 1 . Kals, H.J.J.: XPLANE, a generative computer aided process planning system for part manufacturing. Alınals of CIRP. vol. $35 / 1 / 86,1986$

7 Erve.A.H van 't, Kals.H.J.J.: XPLANE - a knowledgebase-dricen process planning expert system, Proceedings of the Int. Conference on Computer Aided Engineering (CAPE). Edinburgh, april 1986

8 Bruenighaus.G.: Rechnerunterstuetzte Konstruktion von Baukastenvolrichtungen, Ph.D. Thesis, RWTH Aachen, 1979

9 Bruenighaus,G..Pieperhoff.H.J.: Rationalisierung der Vorrichtingskonstruktion, VDI-Verlag, Duesseldorf, 1979

10 Pieperhoff.H.J.: Rechnerunterstuetzte Konstruktion von Vorrichtungen, Ph.D. Thesis, RWTH Aachen, 1979

11 Lock,F.: Konzeption und Entwicklung von Vorrichtungssytemen fuer clie spanende Feltigung, Ph.D. Thesis, RWTH Aachen, 1984

12 Boelma,J,R.: Description of the CAF sy'stem (final report), Report PT 283 (confidential), University of Twente. 1985, (in Dutch)

13 Boerma,J.R.:The FlXES sy'stem, Report PT 298, University of Twente 1986, (in Dutch)

14 Boerna,J.J.,Kals,H.J.J.: FIXES, a computer aided planning and design system for jigs \& fixtures, Report PT 313, University of Twente, 1987

15 Erve,A.H.van ' $t$. Kals, H.J.J.: The selection of optimum machining operations in automated process planning, 19th C.IRP International Seminar on Manufacturing Systems. Pean. State University, 1987 